Artigo de Revisão

Revista Saúde.Com

Rev. Saúde.Com 2021; 17(4): 2471- 2480

ISSN 1809-0761

https://periodicos2.uesb.br/index.php/rsc

\title{
INTERVENÇÕES EDUCATIVAS EM MEDICINA TRANSFUSIONAL: UMA REVISÃO INTEGRATIVA
}

\author{
EDUCATIONAL INTERVENTIONS IN TRANSFUSION MEDICINE: A \\ SYSTEMATIC REVIEW
}

\author{
Vitória de Souza Siqueira, Silvestre Savino Neto
}

Fundação Santa Casa de Misericórdia do Pará

\begin{abstract}
The lack of knowledge on the part of health professionals can lead to an increased risk of mortality and morbidity associated with blood transfusion. The curricula offer little space for this topic. The present study aims to analyze educational interventions in transfusion medicine. For that, the electronic databases were consulted, from the descriptors: Transfusion, Transfusion Medicine and Health Education. Several options are proposed educational interventions. It is necessary that these are established in the form of continuing education and that a rigorous validated evaluation process be applied.
\end{abstract}

Keywords: Transfusion, Transfusion Medicine, Health Education
Resumo

A falta de conhecimento por parte dos profissionais de saúde pode levar a um aumento do risco de mortalidade e morbidade associada à transfusão de sangue. Os currículos oferecem pouco espaço para esse tema. O presente estudo objetiva analisar as intervenções educativas em medicina transfusional. Para isso, consultaram-se bases eletrônicas de dados, a partir dos descritores: Transfusão, Medicina Transfusional e Educação em Saúde. Várias são as opções propostas como intervenções educacionais. É necessário que estas se estabelecem na forma de educação continuada e que um processo avaliativo rigoroso validado seja aplicado.

Palavras-chave: Transfusão, Medicina Transfusional, Educação em Saúde 
A transfusão de sangue é um procedimento que salva vidas, mas apresenta riscos. Cada produto sanguíneo transfundido acarreta um risco de efeitos colaterais precoces ou tardios e isso deve ser sempre levado em consideração ${ }^{1}$. O suporte transfusional ideal é caracterizado por fornecer os hemocomponentes certos, na quantidade certa, ao paciente certo, no momento certo ${ }^{2}$. o processo transfusional traz a intervenção de muitos atores (equipes médicas, suporte, equipe de laboratório) que devem ter um perfeito entendimento de seu papel em um contexto global e de seus limites ${ }^{3}$.Como existe a possibilidade de erro em todas as etapas do procedimento, a estreita colaboração dos médicos e o conhecimento suficiente da equipe são essenciais para a utilização adequada desses produtos e transfusão segura $^{4-5}$.

Embora o conhecimento nem sempre reflita as melhores práticas, uma educação adequada em medicina transfusional ajuda a promover a segurança do paciente e reduzir os erros de transfusão de sangue ${ }^{6}$. No ano de 2019, foram relatados 4.248 eventos adversos no Serious Hazards of Transfusion (SHOT) ${ }^{7}$, do total de eventos, $84,1 \%$ resultaram de erros ou "fatores humanos" e apenas 10,3\% não foram evitáveis. Estudos evidenciam a deficiência no conhecimento dos profissionais de saúde, sobre hemotransfusão, bem como, a necessidade de treinamento e orientação ${ }^{8-10}$. Estudos realizados nos Estados Unidos e no Brasil relatam que os programas acadêmicos em escolas médicas relacionadas à medicina transfusional são insuficientes. Embora as faculdades de medicina tenham currículos de medicina de transfusão, o tempo gasto no ensino desse material pode variar muito $^{11-15}$.

Em outras palavras, os currículos médicos não incluem medicina transfusional como unidade de aprendizagem. Isso ocorre porque se sente que o conhecimento necessário para realizar as transfusões pode ser adquirido a partir da experiência clínica em vez da educação programada $^{16}$. Como resultado, a tendência é inadvertidamente transfundir de forma inadequada, com riscos concomitantes e desperdício desse recurso raro ${ }^{11}$. As estratégias educacionais em medicina transfusional variam amplamente entre continentes e regiões do mundo, com impacto no abastecimento de sangue. Os currículos dos cursos da área da saúde oferecem pouco espaço para esse tema, com uma abordagem superficial, sendo necessário o estabelecimento de padrões de competências e habilidades em hemoterapia na graduação ${ }^{17}$. Dessa forma, o presente estudo tem como objetivo analisar as intervenções educativas em medicina transfusional de produções científicas nacionais e internacionais.

\section{Metodologia}

O estudo teve uma abordagem qualitativa descritiva, do tipo revisão integrativa de literatura, permitindo a compreensão sobre a temática específica a partir de estudos independentes. A realização do estudo ocorreu por meio de seis etapas: formulação da questão de pesquisa; escolha de descritores; posteriormente definiram-se os critérios de inclusão e exclusão; escolha das informações que deveriam ser extraídas; interpretação e discussão dos resultados e apresentação da síntese das informações. Construiu-se o estudo a partir da seguinte questão norteadora: "Quais as principais produções científicas sobre as intervenções educativas em medicina transfusional?"

Para construção deste estudo consultaram-se as bases eletrônicas de dados Literatura LatinoAmericana e do Caribe em Ciências da Saúde (LILACS via BVS), Scientific Electronic Library Online (SciELO), Medical Literature Analysis and Retrieval System Online (MEDLINE via PubMed). Para a busca utilizaram-se os descritores em Ciências da Saúde (DeCS): Transfusão, Medicina Transfusional e Educação em Saúde empregando-se o operador booleano "AND" para realizar as associações de todos os descritores entre si.

A coleta dos artigos foi realizada nos meses de agosto e setembro de 2019 e como critério de inclusão para seleção do material utilizou-se: materiais com idiomas em português, espanhol e inglês; apenas materiais contidos em periódicos científicos publicados nos anos de 2015 a 2020, que contivessem intervenção educativa.

Foram encontradas inicialmente 346 publicações, das quais 2 estavam duplicadas. Após triagem de título e resumo, selecionaram-se 43 artigos para leitura de texto completo. Destes, 14 apresentavam intervenção educativa e apenas 5 foram publicados nos últimos cinco anos, 
atendendo, portanto, os critérios de elegibilidade. Os detalhes do processo de seleção estão ilustrados na FIGURA 1.

Após a seleção do material os dados foram extraídos a partir de um roteiro sistemático com o objetivo de organizar as informações sintetizadas contidas nos artigos selecionados, tais como: código do artigo, título, autor, ano, país, base de dados, objetivo, intervenção proposta e principais conclusões (TABELAS 1-4).

Figura 1 - Processo de busca, seleção e inclusão de estudos

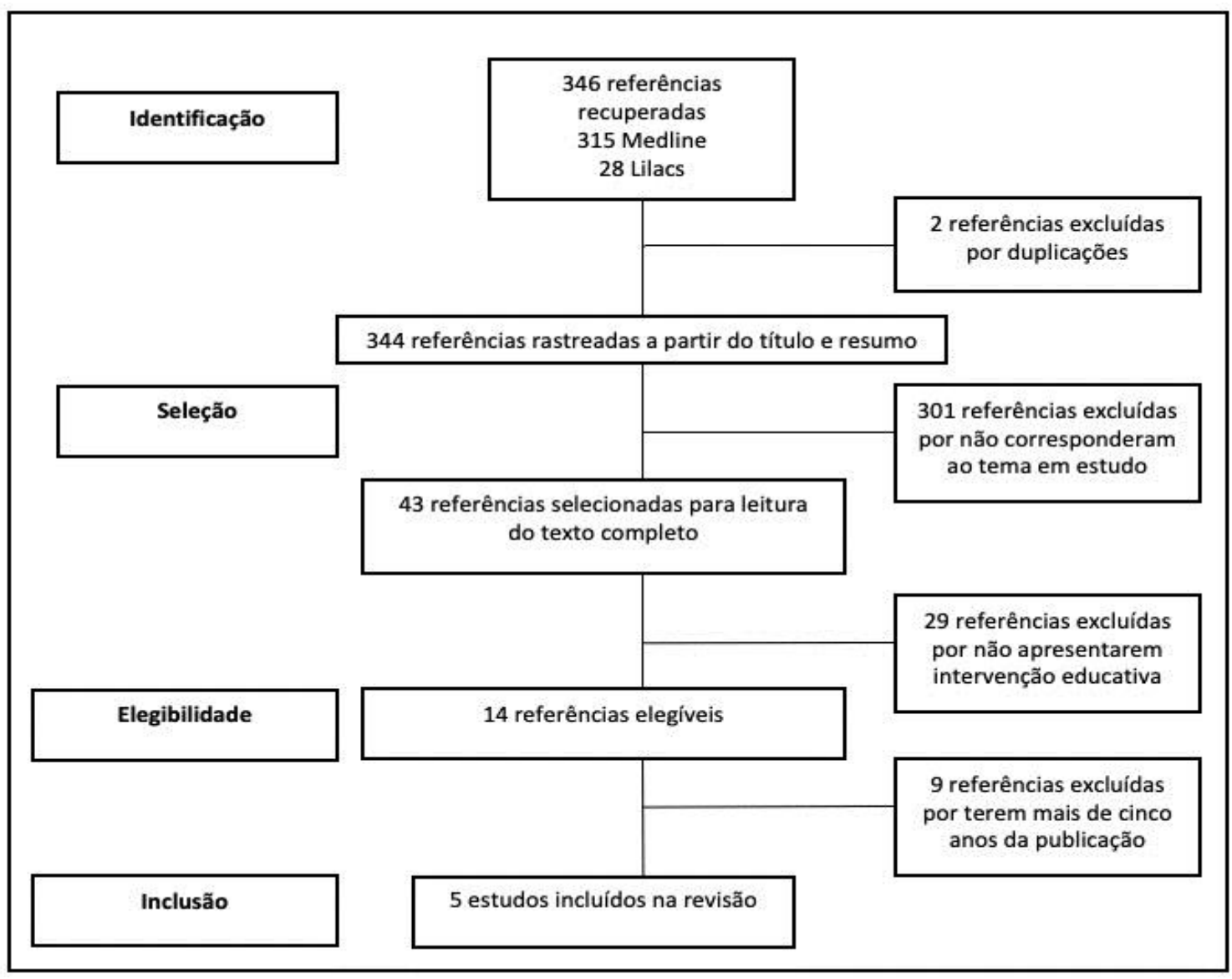




\section{Resultados e Discussão}

A produção científica sobre avaliação do ensino em hemoterapia notoriamente demonstra resultados alarmantes sobre o nível de conhecimento insuficiente dos profissionais da área da saúde em relação ao tema em questão. Em um estudo multicêntrico realizado entre estudantes de medicina, que incluiu 727 (24\%) de 3.009 alunos matriculados em 13 escolas médicas. Na autoavaliação, $65 \%$ dos alunos relataram que a formação em medicina transfusional era insuficiente. Para o início e acompanhamento das transfusões, $52 \%$ se consideraram completamente insuficientes nessa área ${ }^{18}$. Dados semelhantes foram encontrados por Al-Nasr et $a l^{19}$, em 2016, onde pode-se concluir que, a maioria dos enfermeiros estudados possuía nível de conhecimento insatisfatório sobre transfusão sanguínea.

Para avaliação dos conhecimentos e habilidades essenciais para médicos que transfundem hemoderivados, Haspel et $\mathrm{al}^{20}$, em 2014, criaram um exame validado (BEST-TEST) para avaliar com precisão o conhecimento em medicina transfusional, pelo uso do método de Dephi modificado, para garantir a validade do conteúdo, membros de uma organização internacional de especialistas em medicina transfusional (Biomedical Excellence for Safer Transfusion [BEST] Collaborative) participaram do processo de concepção do exame. Assim, acredita-se, que este exame pode ser usado para determinar déficits de conhecimento e auxiliar no planejamento de currículos para melhorar o processo transfusional.

Notou-se, ainda, uma variabilidade na implantação do tema entre os diversos currículos da área da saúde. Por exemplo, em um estudo conduzido nos Estados Unidos, 83\% dos 86 pesquisados relataram que sua escola tinha aulas de hemoterapia, quase metade desse ensino usava apenas 1 ou 2 horas. Apenas 29\% relataram pequenas sessões de grupo relacionadas à medicina transfusional. Além disso, não há dados publicados que tenham determinado a eficácia desses diferentes currículos. Achados semelhantes foram relatados em relação às residências de diferentes especialidades médicas ${ }^{19,21-23}$.

A presente revisão permitiu a convergência de vários estudos que demonstrassem opções de intervenções educativas em hemoterapia, dá-se destaque aqui, ao uso de tecnologias e novas formas de ensino. Dos cinco artigos analisados, um $(\mathrm{A} 1)^{24}$ utilizava a técnica de simulação alta fidelidade (SAF), que vem sendo cada vez mais utilizada nos cursos de graduação e permite que dentro de um ambiente seguro o estudante possa estabelecer um processo de aprendizagem através da experiência e analisar as suas principais deficiências para lapidação de práticas futuras reais. 
Tabela 1 - Análise da Intervenção educacional em medicina transfusional do artigo A1

\begin{tabular}{|c|c|c|c|c|c|c|}
\hline $\begin{array}{c}\text { Código do } \\
\text { Artigo }\end{array}$ & Título & $\begin{array}{l}\text { Autor. Ano. } \\
\text { País }\end{array}$ & $\begin{array}{c}\text { Base de } \\
\text { Dados }\end{array}$ & Objetivo & Intervenção & Conclusão \\
\hline A1 & $\begin{array}{l}\text { Use of high- } \\
\text { fidelity } \\
\text { simulation } \\
\text { to increase } \\
\text { knowledge } \\
\text { and skills in } \\
\text { caring for } \\
\text { patients } \\
\text { receiving } \\
\text { blood } \\
\text { products }\end{array}$ & $\begin{array}{l}\text { Breymier T. } \\
\text { \& } \\
\text { Rutherford- } \\
\text { Hemming T. } \\
\text { (2017). } \\
\text { EUA }^{24}\end{array}$ & Medline & $\begin{array}{l}\text { Descrever a } \\
\text { situação } \\
\text { atual da } \\
\text { ciência } \\
\text { relacionada } \\
\text { ao uso de } \\
\text { simulação na } \\
\text { transfusão de } \\
\text { sangue }\end{array}$ & $\begin{array}{l}\text { Simulação de } \\
\text { alta fidelidade, } \\
\text { cujos objetivos } \\
\text { eram: Identificar } \\
\text { os riscos do } \\
\text { paciente ao } \\
\text { receber } \\
\text { produtos } \\
\text { sanguíneos; } \\
\text { demonstrar o } \\
\text { procedimento } \\
\text { correto para } \\
\text { administração } \\
\text { de } \\
\text { hemoderivados; } \\
\text { reconhecer } \\
\text { sinais e } \\
\text { sintomas de } \\
\text { uma reação } \\
\text { transfusional; } \\
\text { usar } \\
\text { intervenções de } \\
\text { enfermagem } \\
\text { corretas se o } \\
\text { paciente } \\
\text { apresentar } \\
\text { reação à } \\
\text { transfusão e } \\
\text { praticar a } \\
\text { comunicação } \\
\text { terapêutica } \\
\text { apropriada }\end{array}$ & $\begin{array}{l}\text { Simulação de alta fidelidade no } \\
\text { manejo da transfusão de } \\
\text { sangue pode fornecer uma } \\
\text { experiência de aprendizagem } \\
\text { segura e valiosa para os } \\
\text { enfermeiros da equipe, além } \\
\text { de fornecer uma plataforma } \\
\text { para educação interprofissional } \\
\text { A simulação fornece um } \\
\text { ambiente para a prática do } \\
\text { pensamento crítico e } \\
\text { julgamento clínico com } \\
\text { processos de manejo de } \\
\text { transfusão de sangue. }\end{array}$ \\
\hline
\end{tabular}


É fundamental que as instituições sigam os Padrões de Boas Práticas em Simulação, da The International Association for Clinical Simulation and Learning (INACSL) ${ }^{25}$, atualizadas em 2016. As etapas específicas para fornecer uma simulação de alta fidelidade de qualidade na transfusão sanguínea incluem: projeto de SAF para procedimento transfusional estabelecido; tutorial ou palestra antes da simulação; prebriefing (orientação sobre ambiente e manequim, recursos e dados do prontuário do paciente); experiência da simulação e debriefing (avaliação da experiência, que seguirá um modelo estruturado e através de uma comunicação aberta e de confiança, gerará reflexão para práticas futuras aprimoradas).

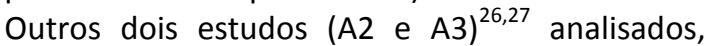
tiveram como principais aliados os recursos tecnológicos, tão comuns na nossa sociedade atual. $\mathrm{O} A 2^{26}$ traz um software educacional, Hemotherapy Quiz, que é estruturado na forma de casos clínicos sobre os diversos temas da medicina transfusional, com cinco opções de alternativas com a melhor conduta a seguir, em seguida o usuário é direcionado para uma explicação sobre o tema e as referências bibliográficas norteadoras. Tal software parece ser uma boa opção quando utilizado como forma complementar de ensino em relação as aulas expositivas e/ou livros didáticos.

Tabela 2 - Análise da intervenção educacional em medicina transfusional do artigo A2

\begin{tabular}{|c|c|c|c|c|c|c|}
\hline $\begin{array}{l}\text { Código do } \\
\text { Artigo }\end{array}$ & Titulo & $\begin{array}{c}\text { Autor. Ano. } \\
\text { Pais }\end{array}$ & $\begin{array}{c}\text { Base de } \\
\text { Dados }\end{array}$ & Objetivo & Intervenção & Conclusão \\
\hline$A 2$ & $\begin{array}{l}\text { Investigaçäo do } \\
\text { conhecimento } \\
\text { de hemoterapia } \\
\text { entre médicos } \\
\text { residentes e } \\
\text { desenvolvimento } \\
\text { de um software } \\
\text { como } \\
\text { ferramenta } \\
\text { educacional }\end{array}$ & $\begin{array}{l}\text { Vaena V. } \\
(2018) . \\
\text { Brasil26 }\end{array}$ & LILACS & $\begin{array}{l}\text { Avaliar } \\
\text { o conhecimento e as } \\
\text { percepçôes sobre a } \\
\text { Hemoterapia de médicos } \\
\text { residentes de hospitais } \\
\text { públicos do Rio de } \\
\text { Janeiro e paralelamente } \\
\text { desenvolver e testar } \\
\text { um software educacional } \\
\text { sobre o tema. }\end{array}$ & $\begin{array}{l}\text { Software - } \\
\text { Hemotherapy } \\
\text { Quiz: } \\
\text { questionário } \\
\text { composto por } \\
10 \text { casos clínicos } \\
\text { que abordam } \\
\text { temas de } \\
\text { hemoterapia, } \\
\text { cada questăo é } \\
\text { composta por } \\
\text { cinco } \\
\text { afirmaçóes, } \\
\text { com apenas } \\
\text { uma escolha } \\
\text { correta. Em } \\
\text { seguida, o } \\
\text { usuário é } \\
\text { direcionado } \\
\text { para uma tela } \\
\text { com a } \\
\text { explicação do } \\
\text { tema. }\end{array}$ & $\begin{array}{l}\text { O software } \\
\text { Quiz } \\
\text { Hemotherapy } \\
\text { foi bem } \\
\text { recebido por } \\
\text { especialistas e } \\
\text { estudantes de } \\
\text { medicina. } \\
\text { Todos os } \\
\text { especialistas } \\
\text { que avaliaram } \\
\text { o questionário } \\
\text { consideraram } \\
\text { que ele traz } \\
\text { beneficios na } \\
\text { compreensåo } \\
\text { do assunto, } \\
\text { podendo } \\
\text { complementar } \\
\text { a leitura do } \\
\text { livro didático e } \\
\text { recomendaram } \\
\text { o uso do } \\
\text { software. }\end{array}$ \\
\hline
\end{tabular}


Já o $A 3^{27}$ faz um comparativo entre esforços educacionais, caracterizados por palestras, que tinham como base uma estratégia transfusional restritiva e a implementação subsequente de um algoritmo no provedor hospitalar utilizado para solicitação de hemocomponentes, que correlacionava-se ao sistema de informações do laboratório e informava ao solicitante se a transfusão encontrava-se dentro das diretrizes de transfusão do hospital. Esse estudo chegou a conclusão, que o algoritmo pode de fato ser útil para manter o impacto sobre a utilização do sangue alcançado por meio da educação.

Tabela 3 - Análise da intervenção educacional em medicina transfusional do artigo A3

\begin{tabular}{|c|c|c|c|c|c|c|}
\hline $\begin{array}{l}\text { Código } \\
\text { do Artigo }\end{array}$ & Título & $\begin{array}{l}\text { Autor. Ano. } \\
\text { País }\end{array}$ & $\begin{array}{l}\text { Base de } \\
\text { Dados }\end{array}$ & Objetivo & Intervenção & Conclusão \\
\hline A3 & $\begin{array}{l}\text { Efficacy of } \\
\text { education } \\
\text { followed by } \\
\text { computerized } \\
\text { provider } \\
\text { order entry } \\
\text { with clinician } \\
\text { decision } \\
\text { support to } \\
\text { reduce red } \\
\text { blood cell } \\
\text { utilization }\end{array}$ & $\begin{array}{l}\text { Zuckerberg } \\
\text { G et al. } \\
\text { (2015). } \\
\text { EUA }^{27} \text {. }\end{array}$ & Medline & $\begin{array}{l}\text { Avaliar as } \\
\text { mudanças na } \\
\text { utilização de } \\
\text { concentrado } \\
\text { de hemácias } \\
\text { associadas as } \\
\text { intervenções: } \\
\text { educação } \\
\text { sobre as } \\
\text { diretrizes de } \\
\text { transfusão } \\
\text { baseadas em } \\
\text { evidência e a } \\
\text { solicitação } \\
\text { informatizada } \\
\text { pelo provedor } \\
\text { como suporte } \\
\text { de decisão do } \\
\text { médico }\end{array}$ & $\begin{array}{l}\text { Série de palestras } \\
\text { sobre prática de } \\
\text { transfusão baseada } \\
\text { em evidências com } \\
\text { apoio a uma } \\
\text { estratégia } \\
\text { transfusional } \\
\text { restritiva; riscos de } \\
\text { transfusão e } \\
\text { benefícios, além de } \\
\text { auditorias de } \\
\text { transfusão } \\
\text { trimestrais } \\
\text { Implementação do } \\
\text { algoritmo de } \\
\text { suporte a decisão } \\
\text { clínica no provedor } \\
\text { de solicitação } \\
\text { informatizada de } \\
\text { hemocomponentes } \\
\text { com alerta de } \\
\text { melhores práticas }\end{array}$ & $\begin{array}{l}\text { Ao implementar uma } \\
\text { combinação de campanhas } \\
\text { educacionais abrangentes com } \\
\text { algoritmos de solicitação } \\
\text { informatizada de } \\
\text { hemocomponentes pelo } \\
\text { provedor e alerta de melhores } \\
\text { práticas, um programa de } \\
\text { gerenciamento de sangue } \\
\text { provavelmente terá sucesso na } \\
\text { redução de riscos, melhoria de } \\
\text { resultados e redução de } \\
\text { custos. }\end{array}$ \\
\hline
\end{tabular}


Em contrapartida o artigo $\mathrm{A}^{28}{ }^{28}$, utiliza uma intervenção mais tradicional, nomeada de Transfusion Camp, marcada por sessões de palestras e seminários de imersão ao longo do ano letivo. A estratégia de ser ao longo do ano ao invés de um módulo pontual, faz com que está intervenção proporcione uma educação mais continuada e uma perspectiva de fixação do conteúdo a longo prazo. $\mathrm{O}$ artigo $\mathrm{A} 5^{29}$, reconhece formas combinadas de tecnologias para ensino, durante um mês, foram realizadas capacitações em formato de aulas interativas utilizando o recurso audiovisual dos computadores de cada setor, seguindo uma programação previamente agendada e divulgada para garantir a presença e participação de profissionais, além de cartilhas, guia técnico para transfusão de sangue disponível em todos os computadores do hospital e um boletim informativo da gestão dedicado à divulgação do uso racional de hemoderivados.

Tabela 4 - Análise da intervenção educacional em medicina transfusional do artigo A4 e A5

\begin{tabular}{|c|c|c|c|c|c|c|}
\hline $\begin{array}{c}\text { Código } \\
\text { do Artigo }\end{array}$ & Título & $\begin{array}{c}\text { Autor. Ano. } \\
\text { País }\end{array}$ & $\begin{array}{c}\text { Base de } \\
\text { Dados }\end{array}$ & Objetivo & Intervenção & Conclusão \\
\hline A4 & $\begin{array}{l}\text { Evaluation of } \\
\text { "Transfusion } \\
\text { Camp", a } \\
\text { postgraduate } \\
\text { transfusion } \\
\text { medicine } \\
\text { education } \\
\text { program } \\
\text { using the } \\
\text { BEST-TEST } \\
\text { knowledge } \\
\text { assessment } \\
\text { tool }\end{array}$ & $\begin{array}{l}\text { Lin Y et al. } \\
\text { (2015). } \\
\text { Canadáz8 }\end{array}$ & Medline & $\begin{array}{l}\text { Relatar o uso } \\
\text { da ferramenta } \\
\text { validada de } \\
\text { avaliação de } \\
\text { conhecimento } \\
\text { em medicina } \\
\text { de transfusão } \\
\text { BEST-TEST na } \\
\text { avaliação da } \\
\text { intervenção } \\
\text { "Campo de } \\
\text { Transfusão" } \\
\text { da } \\
\text { Universidade } \\
\text { de Toronto }\end{array}$ & $\begin{array}{l}\text { Transfusion } \\
\text { Camp: Cinco } \\
\text { sessões de } 1 \text { dia } \\
\text { ao longo do ano } \\
\text { letivo, } \\
\text { totalizando } 18 \\
\text { horas de } \\
\text { palestras } \\
\text { didáticas e 11,5 } \\
\text { horas de } \\
\text { seminários } \\
\text { interativos } \\
\text { disponibilizada } \\
\text { para todos os } \\
\text { médicos } \\
\text { residentes }\end{array}$ & $\begin{array}{l}\text { A intervenção promoveu melhoria } \\
\text { consistente e geral no } \\
\text { conhecimento dos participantes, } \\
\text { independentemente de seu } \\
\text { programa de treinamento de } \\
\text { residência, e destacou tópicos } \\
\text { específicos de medicina } \\
\text { transfusional que merecem foco } \\
\text { no planejamento curricular. }\end{array}$ \\
\hline A5 & $\begin{array}{l}\text { Practices for } \\
\text { rational use } \\
\text { of blood } \\
\text { components } \\
\text { in a } \\
\text { universitary } \\
\text { hospital }\end{array}$ & $\begin{array}{l}\text { Leão S et al } \\
(2015) \text {. } \\
\text { Brasil }^{29}\end{array}$ & LILACS & $\begin{array}{l}\text { Produzir } \\
\text { melhorias nas } \\
\text { práticas } \\
\text { transfusionais } \\
\text { por meio da } \\
\text { implantação } \\
\text { de um } \\
\text { programa } \\
\text { educacional } \\
\text { para } \\
\text { profissionais } \\
\text { de saúde em } \\
\text { um hospital } \\
\text { universitário }\end{array}$ & $\begin{array}{l}\text { Programa de um } \\
\text { mês composto } \\
\text { por guia técnico, } \\
\text { cartilha } \\
\text { impresso, } \\
\text { boletim } \\
\text { informativo de } \\
\text { gestão e serviço } \\
\text { de capacitação } \\
\text { em formato de } \\
\text { aulas } \\
\text { interativas. }\end{array}$ & $\begin{array}{l}\text { Melhora significativa em todo o } \\
\text { processo transfusional após a } \\
\text { intervenção. O desenvolvimento } \\
\text { de um programa de educação } \\
\text { continuada é necessário, para que } \\
\text { os ganhos com o projeto não } \\
\text { sejam perdidos. }\end{array}$ \\
\hline
\end{tabular}


Assim, é clara que uma combinação entre formas de aprendizado tradicionais, como palestras e aulas expositivas, complementadas por novos recursos e tecnologias, como softwares, simulações, ebooks, além de algoritmos em provedores hospitalares que possam delimitar e reforçar a prática diária baseada em evidências, desde que continuadas ao invés de pontuais parece ser uma abordagem interessante $\mathrm{e}$ efetiva. Aliado a isto, uma normatização que abranja todos os cursos da área da saúde, permitirá um alinhamento realista e palpável para um ensino adequado da medicina transfusional, além de promover uma politica de uso racional do sangue, sucesso na redução de riscos, melhoria dos serviços prestados e redução de custos. Além disso, é estimulante que esses resultados sejam evidenciados e divulgados na comunidade pertencente para que o estudante e os servidores percebam o desenlace de seus esforços.

\section{Considerações finais}

Em suma, nota-se uma grande fragilidade no ensino da medicina transfusional nacional e internacional, o que gera a necessidade de um aprimoramento dos currículos dos profissionais da área da saúde, que contemple indicações e manejo adequado para o estabelecimento de práticas de transfusão seguras. Várias são as opções propostas pela literatura como formas de intervenções educacionais com bons resultados identificados: software, simulação de alta fidelidade, guia hospitalar, cartilha, algoritmo de suporte a decisão clinica no provedor utilizado pelo hospital, programas educativos que alberguem palestras, aulas remotas, auditorias e boletins da gestão hospitalar, para análise dos resultados obtidos pela intervenção. É necessário que estas intervenções se estabelecem na forma de educação continuada e que um processo avaliativo rigoroso validado, por exemplo, através do BEST-TEST, seja aplicado intermitentemente, para que a qualidade da prática transfusional perdure. Ademais, constatou-se, a carência de estudos que abordem a temática em questão, dessa forma, espera-se que tal estudo seja um estímulo para novas produções científicas.

\section{Referências}

1. Chakravarty-Vartak U, Shewale R, Vartak S, Faizal F, Majethia N. Adverse Reactions of Blood Transfusion: A Study in a Tertiary Care Hospital. Int J Sci Stud 2016;4(2):90-94.
2. Laher $\mathrm{M}$, Patel $\mathrm{M}$. Assessment of the knowledge of usage of blood and blood products amongst medical doctors in the Department of Medicine at the Faculty of Health Sciences, University of the Witwatersrand affiliated academic hospitals. Transfusion and Apheresis Science 2019;58(1):43-47.

3. Zuckerberg G, Scott A, Wasey J, Wick E, Pawlik T, Ness P, Patel N, Resar L, Frank S. Efficacy of education followed by computerized provider order entry with clinician decision support to reduce red blood cell utilization. Transfusion 2015; 55:1628-1636.

4. Eichbaum Q, Murphy M, Liu Y, Kajja I, Hajjar L, Sibinga S, Shan H. Patient Blood Management: An International Perspective. Anesth Analg 2016;123(6): 1574-1581.

5. Kasraian L.The awareness of medical staff of hospitals in Shiraz about transfusion medicine and the impact of education. Scientific Journal of Iranian Blood Transfusion Organization. 2014;11(3).

6. Delaforce A, Duff J, Munday J, Hardy J. Overcoming barriers to evidence-based patient blood management: a restricted review. Implementation Science 2020; 15 (6): 2-13.

$7 . \quad$ Serious Hazards of Transfusion (SHOT). Annual Shot Repport. Serious Hazards of Transfusion (SHOT); 2020.

8. World Health Organization (WHO). AideMémoire for National Health Programmes: Blood Safety. World Health Organization (WHO); 2013.

9. Silva $K$, Duarte R, Floriano D, Andrade L, Tavares J, Felix M, Zuffi F, Pires P, Barbosa M. Blood transfusion in Intensive Care Units: knowledge of the nursing team. Av Enferm. 2017; 35(3):313-323.

10. Encan B, Akin S. Knowledge of Blood Transfusion Among Nurses. The Journal of Continuing Education in Nursing 2019; 50 (4): 176-182.

11. Vaena M, Alves L. Assessment of the knowledge and perceptions of Brazilian medical residents on transfusion medicine. Hematol Transfus Cell Ther 2019;41(1):37-43.

12. Kupesiz F, Ocak S, Koc B, Evim M, Tufekci O, Kintrup G, Aygunes U, Eker I, et al. Evaluation of the knowledge of intern doctors on transfusion medicine in Turkey. Research Square 2020; 1-20.

13. Al-Nasr M, Razik B, Mohamed M, AlMezaien M. Nurse's performance regarding caring of patients undergoing blood transfusion. Port Said Scientific Journal of Nursing 2016; 3 (2). 14. Duguid J; Copplestone, J. Teaching transfusion in UK medical schools: a survey by the National Blood Transfusion Committee. 
Medical Education 2008, 42, 439-442.

15. Karp J, Weston C, King K. Transfusion medicine in American undergraduate medical education. Transfusion 2011; 51(11):2470-2479.

16. The Joint Commission and the American Medical Association-Convened Physician Consortium for Performance Improvement (PCPI). Proceedings from the National Summit on Overuse. 2012.

17. Mohammad V. The Impact of an Educational Program on Blood and Blood Products Transfusion on Nurses' Level of Knowledge and Performance. Journal of Medicine and Life 2018; 11(3): 238-242.

18. Sack F, Alex M, Chemegni B, Elwige G, Pierre $O$. Evaluation of transfusionnal practices carried out by doctors and paramedics staffs at the Yaounde Central Hospital (Cameroon). The Journal of Medical Research 2018; 4(2): 59-62.

19. Al-Nasr M, Razik B, Mohamed M, AlMezaien M. Nurse's performance regarding caring of patients undergoing blood transfusion. Port Said Scientific Journal of Nursing 2016; 3 (2). 20. Haspel R, Lin Y, Fisher P, Ali A, Parks E. Development of a validated exam to assess physician transfusion medicine knowledge. Transfusion 2014; 54(5): 1225-1230.

21. Kupesiz F, Ocak S, Koc B, Evim M, Tufekci O, Kintrup G, Aygunes U, Eker I, et al. Evaluation of the knowledge of intern doctors on transfusion medicine in Turkey. Research Square 2020; 1-20.

22. Duguid J; Copplestone, J. Teaching transfusion in UK medical schools: a survey by the National Blood Transfusion Committee. Medical Education 2008, 42, 439-442.

23. Karp J, Weston C, King K. Transfusion medicine in American undergraduate medical education. Transfusion 2011; 51(11):2470-2479.

24. Breymier T, Rutherford-Hemming T. Use of high-fidelity simulation to increase knowledge and skills in caring for patients receiving blood products. Crit Care Nurs Clin N Am 2017.

25. INACSL Standards Committee (2016, December). INACSL standards of best practice: Simulation SM Design da Simulação. Clinical Simulation in Nursing 2016; 12(S), 5-12.

26. Vaena M. Investigação do conhecimento de hemoterapia entre médicos residentes $e$ desenvolvimento de um software como ferramenta educacional. Rio de Janeiro; 2018.

27. Zuckerberg G, Scott A, Wasey J, Wick E, Pawlik T, Ness P, Patel N, Resar L, Frank S. Efficacy of education followed by computerized provider order entry with clinician decision support to reduce red blood cell utilization. Transfusion 2015; 55:1628-1636.
28. Lin Y, Cserti-Gazdewich C, Callum J. Evaluation of "Transfusion Camp", a postgraduate transfusion medicine education program using the BEST-TEST knowledge assessment tool. Transfusion 2015; 55:20492051.

29. Leão $S$, Gomes $M$, Aragão $M$, Lobo I. Practices for rational use of blood components in a universitary hospital. Rev Assoc Med Bras 2015; 61(4):355-361.

\section{Endereço para Correspondência}

Vitória de Souza Siqueira

Travessa Francisco Caldeira Castelo Branco, 1708

Vila Dona Mariinha, casa 87.

Bairro Guamá - Belém - Pará

CEP: $66065-310$

E-mail: vitoriasiqueira21@gmail.com

Recebido em 04/09/2021

Aprovado em 28/12/2021

Publicado em 30/12/2021 